Research Article

\title{
Experimental Investigation on the Friction-Induced Vibration with Periodic Characteristics in a Running-In Process under Lubrication
}

\author{
Di Sun $\mathbb{D}^{2},{ }^{2}$ Pengfei Xing $\mathbb{D}^{1},{ }^{1}$ Guobin Li $\mathbb{D}^{,},{ }^{1}$ Hongtao Gao, ${ }^{3}$ Sifan Yang $\mathbb{D}^{1},{ }^{1}$ Honglin Gao $\mathbb{D}^{1}$, \\ and Hongpeng Zhang $\mathbb{B}^{1}$ \\ ${ }^{1}$ Marine Engineering College, Dalian Maritime University, Dalian 116026, China \\ ${ }^{2}$ Marine Engineering College, Jimei University, Xiamen 361021, China \\ ${ }^{3}$ Naval Architecture and Ocean Engineering College, Dalian Maritime University, Dalian 116026, China
}

Correspondence should be addressed to Guobin Li; guobinli88@163.com

Received 13 September 2021; Revised 25 October 2021; Accepted 3 November 2021; Published 24 November 2021

Academic Editor: Selçuk Erkaya

Copyright (C) 2021 Di Sun et al. This is an open access article distributed under the Creative Commons Attribution License, which permits unrestricted use, distribution, and reproduction in any medium, provided the original work is properly cited.

\begin{abstract}
This paper investigated the friction-induced vibration (FIV) behavior under the running-in process with oil lubrication. The FIV signal with periodic characteristics under lubrication was identified with the help of the squeal signal induced in an oil-free wear experiment and then extracted by the harmonic wavelet packet transform (HWPT). The variation of the FIV signal from runningin wear stage to steady wear stage was studied by its root mean square (RMS) values. The result indicates that the time-frequency characteristics of the FIV signals evolve with the wear process and can reflect the wear stages of the friction pairs. The RMS evolution of the FIV signal is in the same trend to the composite surface roughness and demonstrates that the friction pair goes through the running-in wear stage and the steady wear stage. Therefore, the FIV signal with periodic characteristics can describe the evolution of the running-in process and distinguish the running-in wear stage and the stable wear stage of the friction pair.
\end{abstract}

\section{Introduction}

In tribology, when friction pairs are brought together to slide relative with one another under a non-zero normal force, the initial wear process is referred to as running-in [1]. In the running-in process, the mating surfaces of the friction pair gradually become adequate fitting. Studies $[2,3]$ have proved that the running-in has an important influence on improving the performance and service life of the friction pair. Therefore, monitoring and identifying the running-in process of the friction pair are significant to improve the reliability and the economy of the equipment [4].

The running-in process of friction pair can be monitored through the tribological characteristics, such as surface morphology [5], wear rate [6], oil analysis [7], friction signal [8], and so on. However, it is challenging to directly obtain the surface morphology and wear rate of friction pairs in real time during the equipment operation. Also, oil analysis is mostly used for monitoring the equipment offline regularly at present. Friction signals, including the friction-induced vibration (FIV) [9], the friction coefficient [10], the friction heat [11], and the friction force [12], can be collected online without interrupting the operation of mechanical equipment and characterizing the wear state. Therefore, the friction signal is an ideal means to monitor the running-in process. Because the FIV signal contains lots of information on a friction-wear process and can be collected easily, the FIV signal is suitable for monitoring the running-in process.

According to $[13,14]$, two types of FIV signals can be generated in a friction-wear process. One is the FIV signal with a large amplitude and lumping on a narrow frequency band (hereinafter referred to as the periodic FIV), such as the brake squeal [15]. The other type of FIV signal is with small amplitudes and distributes in a wide frequency band (henceforth called the aperiodic FIV), usually referred to as surface or roughness noise [16]. Scholars have conducted 
extensive studies on monitoring the running-in process by the aperiodic FIV signal. For example, Ding et al. [17] found that the friction noise attractor is chaotic, and the attractor evolution of friction noise can help identify the wear process. Zhou et al. [18] studied the correlation between the aperiodic FIV and friction coefficient under different friction states by cross recurrence plot. $\mathrm{Xu}$ et al. [19] characterized the surface wear state of a sliding-rolling contact through the features of the aperiodic FIV. Yu et al. [20] identified the friction state through the frequency band energy of the aperiodic FIV. Thus, the wear process can be characterized by the aperiodic FIV. However, since the aperiodic FIV distributes in a wide frequency range, its amplitude variation must be analyzed by the wear experiments to investigate whether the extracted vibration signal could indicate the friction behavior, which is problematic in a practical application.

Fortunately, because the frequency of periodic FIV is close to the system's natural frequency, it can be identified effectively [21]. Scholars have proved that normal load, surface roughness, sliding velocity, and so on have an important influence on the FIV with periodic characteristics [22-25], which indicates that the periodic FIV is suitable for wear state evaluation. However, the periodic FIV is so weak that it often submerges in background noise under oil lubrication conditions. Therefore, the periodic FIV under oil lubrication has not received the attention it deserves $[26,27]$. As a result, the periodic FIV characteristics in the running-in process are still unrevealed, and further investigation is still needed.

In this paper, a running-in experiment of ball-disk friction pair was carried out on a test rig to fulfill this goal. The particular focus is put on extracting the periodic FIV under oil lubrication and studying its evolution process and transition mechanism in the running-in process. This work is organized as follows. Firstly, the experimental details are illustrated in Section 2. Then, the workflow of the experiment and the data processing is elaborated briefly in Section 3. Then, in Section 4 , the extraction methods of the periodic FIV signals using the harmonic wavelet packet transform (HWPT) are elaborated in detail, and the evolution process and transition mechanism of the periodic FIV in different wear stages are investigated, respectively, by the root mean square (RMS) and the composite surface roughness. In the end, the conclusions are drawn in Section 5.

\section{Experimental Details}

2.1. Experimental Equipment. The ball-on-disk running-in experiments were conducted on a friction-abrasion testing machine (model CFT-I, Zhongkekaihua), as illustrated in Figure 1. In Figure 1 1(a), an electrical motor with rotational speed from $0-2000 \mathrm{r} / \mathrm{min}$ is used to drive the movable bench reciprocating in the stroke of $1-25 \mathrm{~mm}$ through an eccentric mechanism. The disk specimen is mounted on a movable bench firmly by a hold-down plate and moves together. The ball specimen is installed on the load device and remains stationary in the experiment. In the experiment, the ball specimen is pressed on the disk specimen by the load device. The load pressed on the ball specimen can be regulated from 10 to $200 \mathrm{~N}$. The friction force between the ball and disk specimen is measured by the force sensor, processed by the data acquisition system of the testing machine, and finally recorded in the form of friction coefficient. A triaxial accelerometer (model 356 A16 ICP, PCB Piezotronics) with a sensitivity of $10 \mathrm{mV} / \mathrm{g}$ and a range of $\pm 50 \mathrm{~g}$ is fixed on the disk specimen's lower surface to measure the vibration signal. A signal collecting device (INV-3062T2, China Orient Institute of Noise \& Vibration) stores the vibration signals into the computer. The surface roughness of the balldisk friction pair is measured by a confocal laser scanning microscope (OLS4000, Olympus Corporation).

2.2. Friction Pairs. The ball and disk specimens are used as the friction pair for the running-in experiment, as depicted in Figure 1(b). The ball specimen is composed of GCr15 steel with $\Phi 6 \mathrm{~mm}$ diameter and hardness of $750 \mathrm{HV}$. The disk specimen is made up of cast iron with $\Phi 16 \mathrm{~mm}$ diameter and hardness of $480 \mathrm{HV}$.

\subsection{Experiment Method}

2.3.1. Running-In Experiment under Lubrication. The drop lubricated running-in experiments were carried out under ambient condition ( $293 \mathrm{~K}, 45 \%$ relative humidity). The lubricant was CD 40 lubricating oil, an ordinary marine lubricant. The amount of lubricating oil used in the experiment was $200 \mathrm{ml}$. In the testing, the ball specimen was pressed on the upper surface of the disk specimen under a load of $100 \mathrm{~N}$ and remained stationary. The disk specimen was driven to reciprocate in the stoke of $5 \mathrm{~mm}$ by the motor with a rotational speed of $400 \mathrm{r} / \mathrm{min}$. The calculated Hertz contact stress between the friction pair was $3 \mathrm{GPa}$, and a calculated relative sliding velocity between the two was $0.067 \mathrm{~m} / \mathrm{s}$. Three running-in wear tests were carried out to ensure the repeatability. Each test lasted for 60 minutes, and the averages were calculated.

(1) Setting the Wear Stage. According to the friction coefficient variation trend, the wear stage of the friction pair was set [28]. Specifically, when the friction pair is in a running-in wear stage, the friction coefficient decreases gradually; when the friction coefficient presents a smooth and stable variation, the friction pair is in a stable wear stage. Figure 2 depicts the friction coefficient variation in the running-in experiment. The fitting curve displays that the friction coefficient has a more significant value of 0.129 at the initial moment and then decreases to 0.103 gradually in the first 40 minutes. Finally, the friction coefficient fluctuates around 0.103 from 40 th to 60 th $\mathrm{min}$. Therefore, to facilitate the analysis, the first 40 minutes of the experiment were set as a running-in wear stage, and the 40-60 minutes were set as a stable wear stage.

(2) Collecting Vibration Signals. A signal collecting device was applied to collect the vibration signals every 6 seconds with a sampling interval of $0.039 \mathrm{~ms}$ and 10240 sampling points. In the running-in experiment, 10 groups of acceleration signals were collected every minute. 


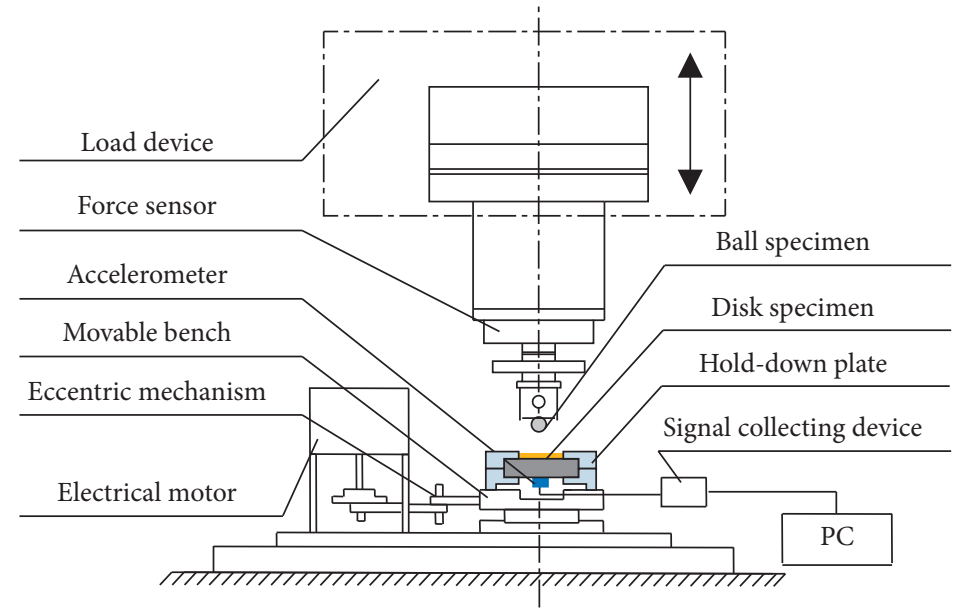

(a)

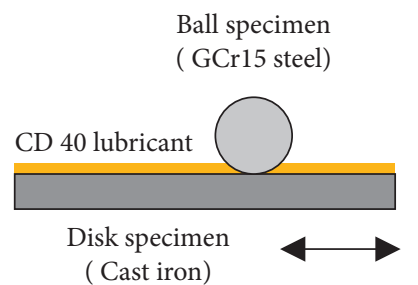

(b)

FIgURE 1: Schematic diagram of the testing machine: (a) testing machine; (b) friction pair.

(3) Measuring Surface Roughness. The surface roughness of the ball and disk specimen was measured by the confocal laser scanning microscope before and after the running-in experiment. A total of 4 groups of surface roughness were obtained. As shown in Figure 3, before the running-in experiment, the surface roughness of the ball specimen $\left(\mathrm{Sa}_{\text {ball-1 }}\right)$ was $0.124 \mu \mathrm{m}$ and that of the disk specimen $\left(\mathrm{Sa}_{\text {disk-1 }}\right)$ was $0.547 \mu \mathrm{m}$; after the experiment, the surface roughness of the ball specimen $\left(\mathrm{Sa}_{\text {ball-2}}\right)$ was $0.554 \mu \mathrm{m}$ and that of the disk specimen $\left(\mathrm{Sa}_{\text {disk-2}}\right)$ was $0.279 \mu \mathrm{m}$.

\subsubsection{Experiments with Squeal under Oil-Free Condition.} To determine the frequency distribution of periodic FIV, a 5minute experiment that can generate squeal noise was conducted under an oil-free condition. In the testing, a test load of $20 \mathrm{~N}$ was applied to the ball specimen, and other conditions were consistent with the lubricated running-in experiment. The initial surface roughness of the ball-disk friction pair was the same as that under the lubricated running-in experiment. Only the squeal signals were collected in the experiment.

2.4. Determination of Lubrication State. The lubrication state was determined by the film thickness ratio $\lambda$ [29], that is, fluid lubrication $(\lambda>3)$, mixed lubrication $(3>\lambda>1)$, and boundary lubrication $(\lambda<1) . \lambda$ is defined as follows:

$$
\lambda=\frac{h_{\min }}{\sigma_{c}}
$$

where $\sigma_{\mathrm{c}}$ is the composite roughness of the two contact surfaces, which can be calculated from equation (2), and $h_{\min }$ is the minimum lubricant film thickness according to Hamrock-Dowson formulation [30,31] given in equations (2)-(4).

$$
\begin{aligned}
\sigma_{c} & =\sqrt{\sigma_{1}^{2}+\sigma_{2}^{2}}, \\
h_{\min } & =7.43 R\left(1-0.85 e^{-0.31 k}\right)\left(\frac{\eta \mu}{E^{*} R}\right)^{0.65}\left(\frac{P}{E^{*} R^{2}}\right)^{-0.21},
\end{aligned}
$$

where $\sigma_{1}$ is the surface roughness of the ball specimen; $\sigma_{2}$ is the surface roughness of the disk specimen; $R$ is the composite radius; and $E^{*}$ is the composite elastic modulus. The two parameters can be calculated from equations (3) and (4), respectively. The other parameter values of equations (3)-(5) are shown in Table 1.

$$
\begin{aligned}
\frac{1}{R} & =\frac{1}{R_{a}}+\frac{1}{R_{b}}, \\
E^{*} & =\frac{2}{1-v_{a}^{2} / E_{a}+1-v_{b}^{2} / E_{b}} .
\end{aligned}
$$

Based on the above data, the lubricant film thickness is $5.51 \mathrm{~nm}$ under a load of $100 \mathrm{~N}$. The film thickness ratio is 0.0098 before the experiment and 0.0089 after the experiment, respectively, that is, $\lambda<1$. Therefore, the running-in experiment was under the boundary lubrication state.

\section{Workflow}

The workflow of the experimental study is depicted in Figure 4. Two types of experiments are conducted. For the experiment under oil-free conditions, only the squeal signal is sampled. For the lubricated running-in experiment, the surface roughness, friction coefficient, and vibration signals are recorded. The power spectrum analysis is then conducted to study the periodic component in the measured signals. By comparing the frequency components of the squeal signal and the vibration signal, the periodic FIV submerged in the vibration signal of the lubricated running-in experiment is identified. Then, the periodic FIV is 


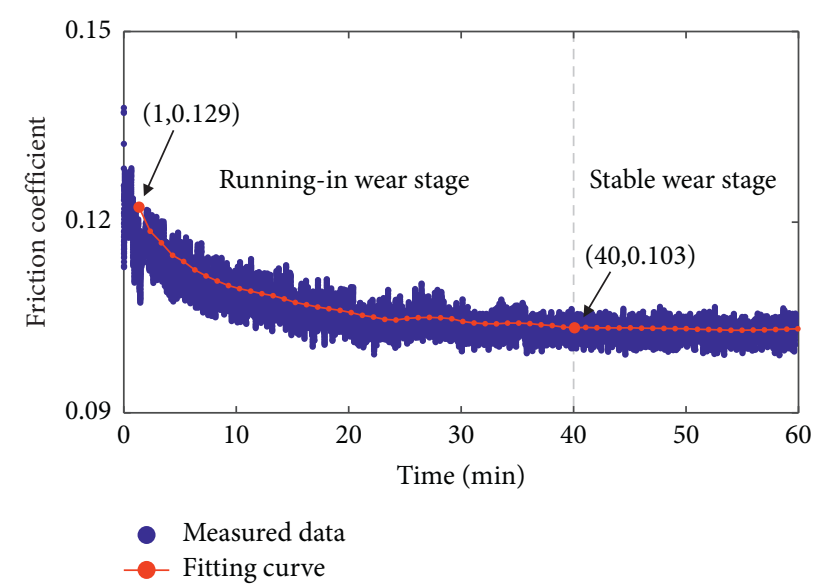

FIGURE 2: Friction coefficient variation in the running-in experiment.

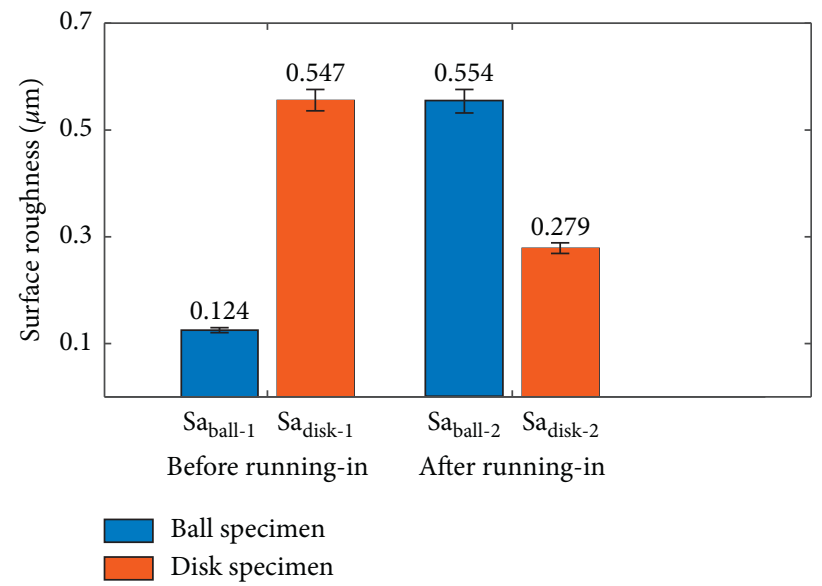

Figure 3: The surface roughness of friction pair.

extracted using the harmonic wavelet packet transform (HWPT) method [33]. Then, the evolution process of the periodic FIV is studied by its RMS. Finally, the evolution mechanism of periodic FIV is discussed with the help of composite surface roughness.

\section{Results and Discussion}

\subsection{Extracting the Periodic FIV Signal}

4.1.1. Time-Frequency Analysis of the Original Vibration Signals. The power spectrum analysis was performed to investigate the periodic components in the original signal better. Figure 5 depicts the waveform and the power spectrum of the original vibration signals at different moments. A log scale is used for the frequency axis to show frequency distribution more clearly in Figure 5(b). Figure 5(a) shows the waveform of the original signals presenting aperiodic variation. However, Figure 5(b) shows multiple prominent periodic components in the original signal, such as $319 \mathrm{~Hz}, 853 \mathrm{~Hz}$, and $2332 \mathrm{~Hz}$. Therefore, there are various periodic components in the measured vibration signals, and the periodic FIV is submerged in the original signal.
4.1.2. Identifying the Frequency of Periodic FIV. The power spectrum analysis was performed on the squeal signal collected under oil-free conditions to identify the frequency of the FIV. Figure 6(a) depicts that the waveform of the squeal signals presents periodic variation obviously; Figure 6(b) shows that the squeal frequency is $2325 \mathrm{~Hz}, 2412 \mathrm{~Hz}$, $2381 \mathrm{~Hz}, 2384 \mathrm{~Hz}$, and $2425 \mathrm{~Hz}$, respectively, with an average of $2385 \mathrm{~Hz}$. According to the hammering model proposed by Rhee [34], the FIV is caused by the hammering action of the asperities between the contact surface similar to that in the modal test, leading to the dominant frequency of the FIV being often consistent with the natural frequency of the tribosystem $[21,35,36]$. Therefore, the natural frequency of the tribosystem is close to $2385 \mathrm{~Hz}$. Correspondingly, the frequency around $2385 \mathrm{~Hz}$ may be the primary frequency component of the periodic FIV in the lubricated running-in experiment, as shown in Figure 5(b).

4.1.3. Features of the Extracted Periodic FIV. The HWPT was carried to extract the high-frequency periodic component from the original signal measured in the lubricated runningin experiment to reduce the noise. Figure 7 depicts the distribution of the high-frequency periodic component and 
TABLE 1: The parameter values.

\begin{tabular}{lcc}
\hline Parameter & Physical meaning & Values \\
\hline$k$ & The ellipticity parameter [32] & 1 \\
$\eta$ & The absolute viscosity of the lubricant & $0.139 \mathrm{~Pa} \cdot \mathrm{s}$ \\
$\mu$ & The mean velocity between the friction pairs & $0.0333 \mathrm{~m} / \mathrm{s}$ \\
$P$ & The normal load & $100 \mathrm{~N}$ \\
$R_{\mathrm{a}}$ & The radius of the ball specimen & $3 \mathrm{~mm}$ \\
$R_{\mathrm{b}}$ & The radius of the disk specimen & Infinite \\
$v_{a}$ & Poisson's ratio of the steel ball & 0.3 \\
$v_{b}$ & Poisson's ratio of the disk & 0.269 \\
$E_{\mathrm{a}}$ & The elastic modulus of the ball & $208 \mathrm{GPa}$ \\
$E_{\mathrm{b}}$ & The elastic modulus of the disk & $209 \mathrm{GPa}$ \\
\hline
\end{tabular}

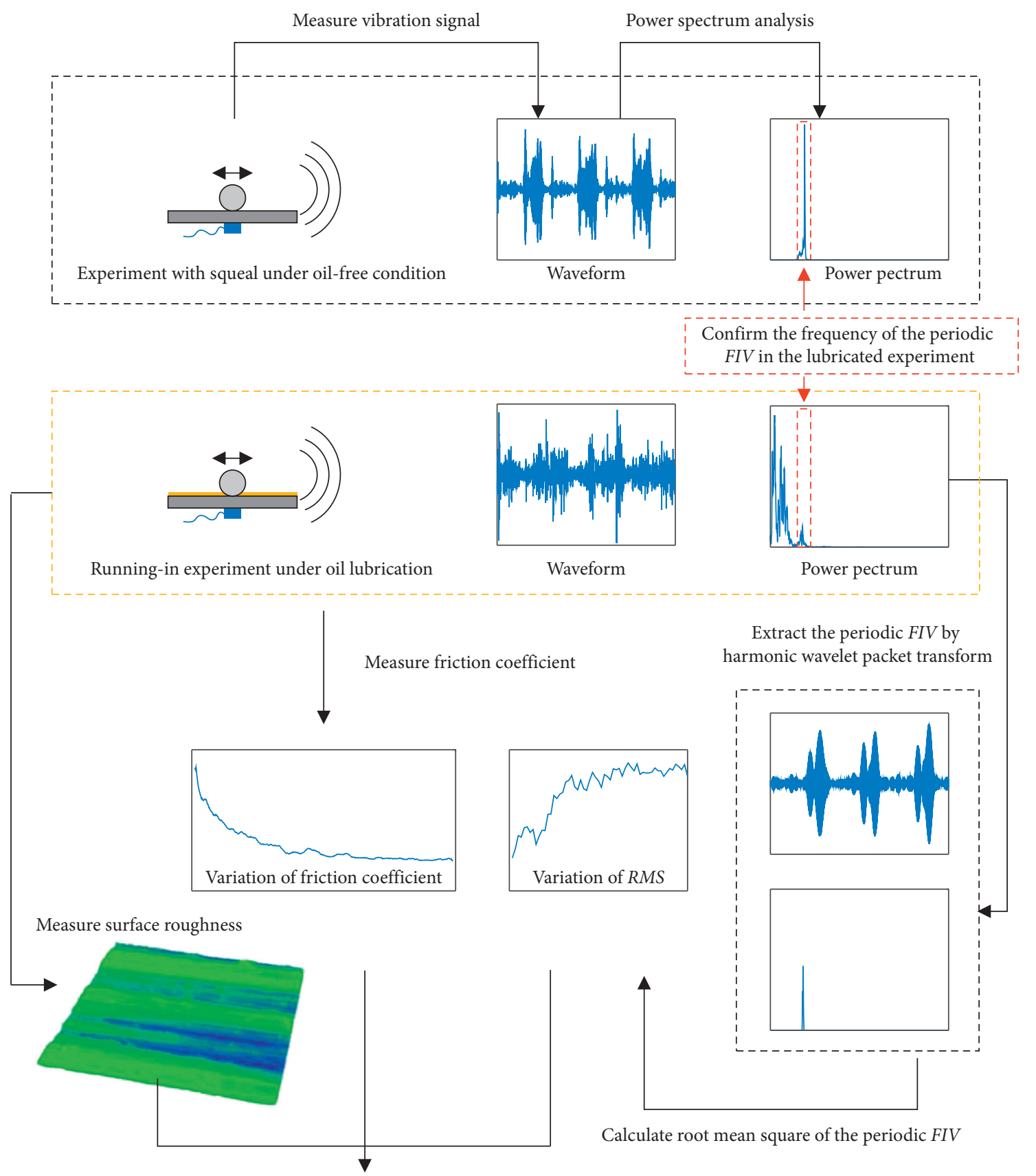

Investigate the evolution of the periodic FIV in different wear states, and reveal the evolution mechanism with the help of the surface roughness

FIgURE 4: The workflow of the experimental study. 


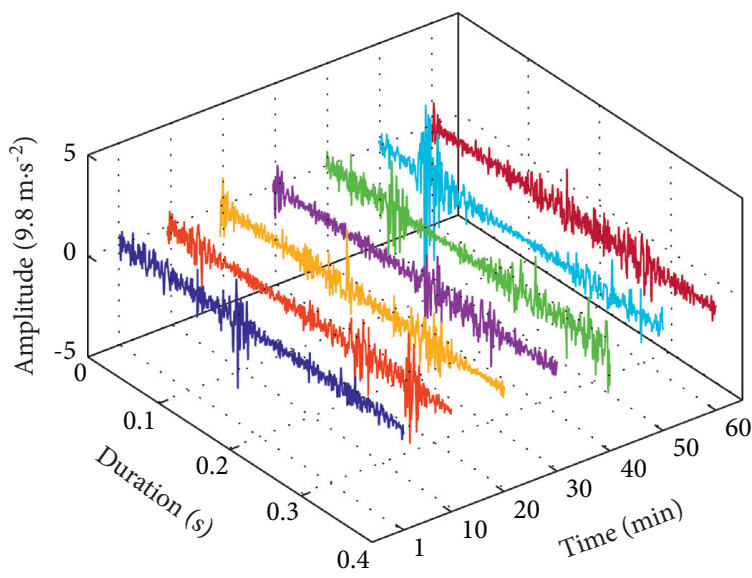

(a)

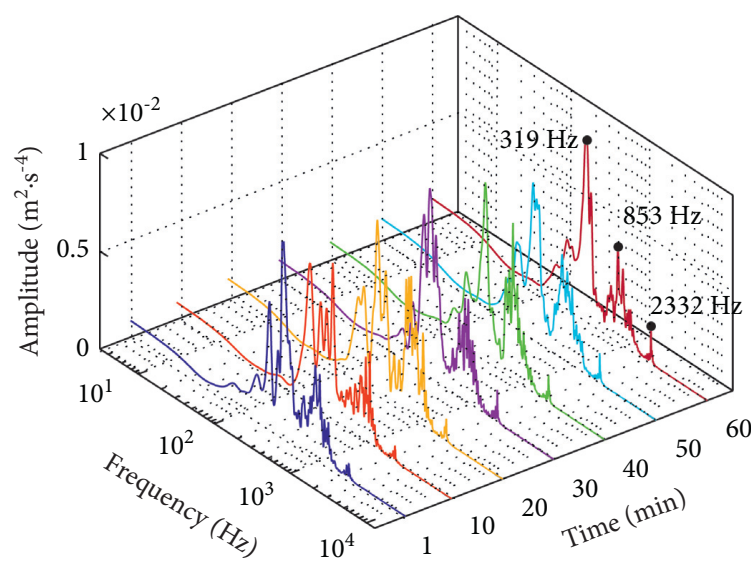

(b)

FIgURE 5: The waveform and power spectrum of original signals under lubricated condition at different moments: (a) the time-domain waveform; (b) the power spectrum.

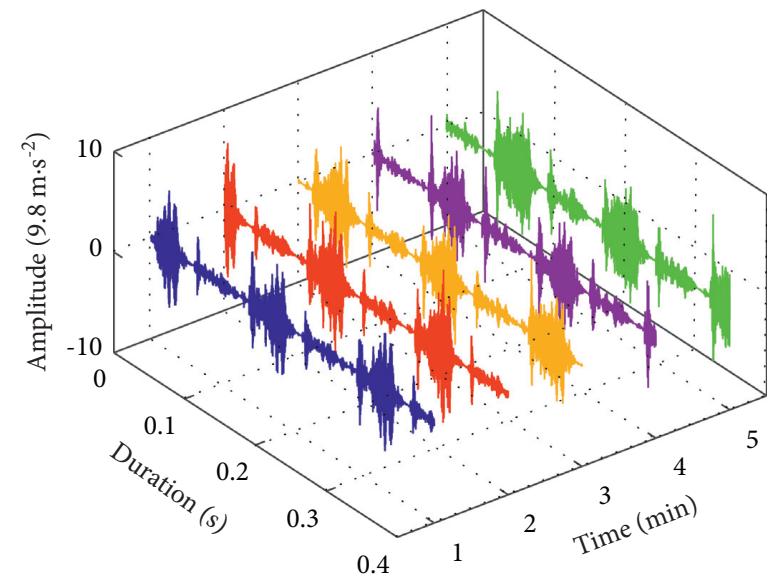

(a)

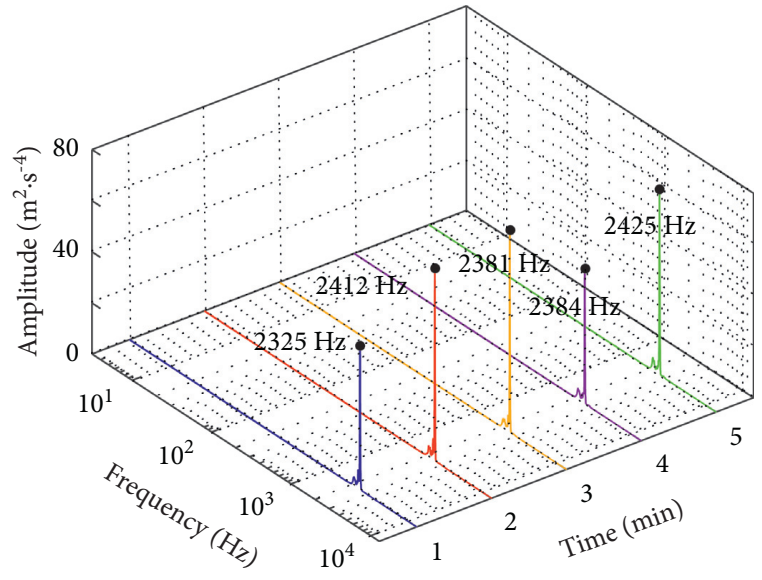

(b)

FIGURE 6: The waveform and power spectrum of squeal signals under dry friction at different moments: (a) the time-domain waveform; (b) the power spectrum.

its amplitude. As illustrated in Figure 7 , the periodic component mainly ranges from $2300 \mathrm{~Hz}$ to $2400 \mathrm{~Hz}$, and there is not much difference in the frequency among different groups of signals. Thus, the components in the frequency band from $2300 \mathrm{~Hz}$ to $2400 \mathrm{~Hz}$ were extracted using HWPT to reconstruct as the periodic FIV signal. More specifically, a 7-level HWPT was carried to decompose the original signals into 128 bands with a width of $100 \mathrm{~Hz}$, and the 23rd frequency band was extracted and reconstructed directly.

The waveform and power spectrum of the extracted periodic FIV signals are shown in Figure 8. It can be seen from Figures 8(a) and 8(b) that the waveform of the extracted FIV signals displays periodic characteristics. Furthermore, the amplitudes of the extracted periodic FIV signals are distinct at different moments in the wear experiment, i.e., the amplitude increases gradually at first and then tends to be stable, indicating that the extracted periodic FIV signal can distinguish the wear state.

\subsection{Evolution of the Periodic FIV}

4.2.1. RMS Variation Law. The RMS of the periodic FIV was calculated, and it displays preferable regularity in different wear states, as shown in Figure 9. Within the first $40 \mathrm{~min}$ of the experiment, the RMS value is small and reveals an upward trend; after the 40th minute, the RMS value is large and fluctuates steadily. According to the experiment condition, the friction pair has also experienced the running-in wear stage (0-40 minutes) and steady wear stage (40-60 minutes), indicating that the extracted periodic FIV is closely related to the wear stage.

4.2.2. Evolution Mechanism. As described in Section 2.4, the running-in experiment was conducted under boundary friction, indicating that the lubricant film was not thick enough to separate the friction surface [37]. Thus, the load was entirely undertaken by the asperities between the friction pair rather than by the lubricant film, demonstrating 


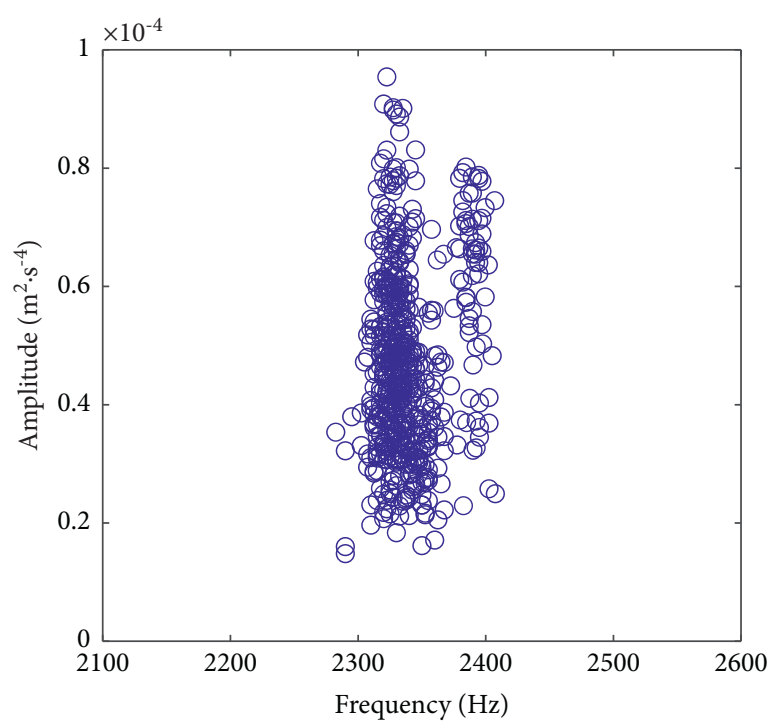

Figure 7: The distribution of high-frequency periodic component.

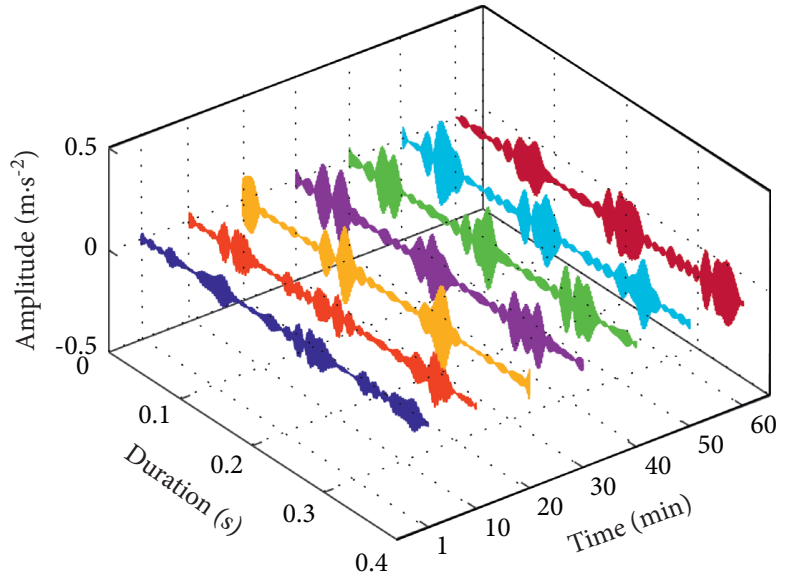

(a)

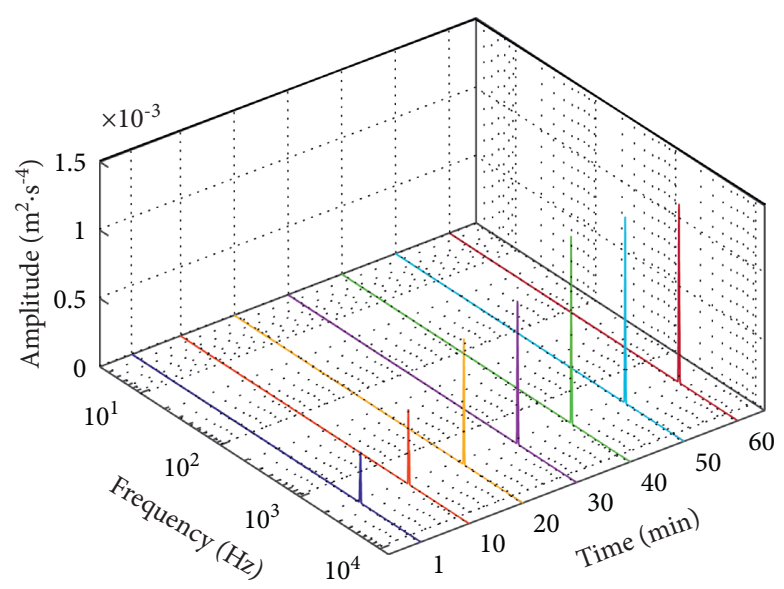

(b)

Figure 8: The waveform and power spectrum of the FIV signals under lubricated condition at different moments: (a) the time-domain waveform; (b) the power spectrum.

that the friction pair was in a strong contact condition [38]. Correspondingly, the periodic FIV was triggered by the hammering action of the asperities between the contact surfaces [34]. Moreover, the film thickness ratio remained stable in the experiment, as calculated from equations (3)-(5), which indicates that the contact condition between the friction pair was mainly affected by the surface roughness. As depicted in Figure 3, the surface roughness of the disk and ball samples shows an opposite variation trend in the test process. Accordingly, it is not comprehensive to study the evolution mechanism of the periodic FIV in the wear process only from the surface roughness of a single sample. Therefore, the evolution mechanism of the periodic FIV is investigated by the composite surface roughness of the friction pair. The specific analysis is as follows.

(1)Running-In Stage (0-40 min). The initial composite roughness of the friction pair is $0.56 \mu \mathrm{m}$ at the beginning of the experiment as calculated from equation (2). According to Figure 3, the surface roughness of the ball specimen is increased by $0.43 \mu \mathrm{m}$ after the experiment, while that of the disk specimen is reduced by $0.268 \mu \mathrm{m}$, indicating that the roughness increase of the ball specimen is greater than the roughness decrease of the disk specimen in the experiment. Thus, the composite roughness increases in the running-in stage. Studies have shown that high surface roughness can reduce the effective contact area $[39,40]$. Therefore, the contact is strengthened progressively under a constant load with the decrease in contact area. As the contact strength increases, the hammering action of the asperities is also enhanced. As a result, the intensity of the periodic FIV triggered by the contact is also progressively enlarged. Correspondingly, the RMS of the extracted periodic FIV signals is small initially, and then it shows an upward trend in the running-in, as shown in Figure 9. 


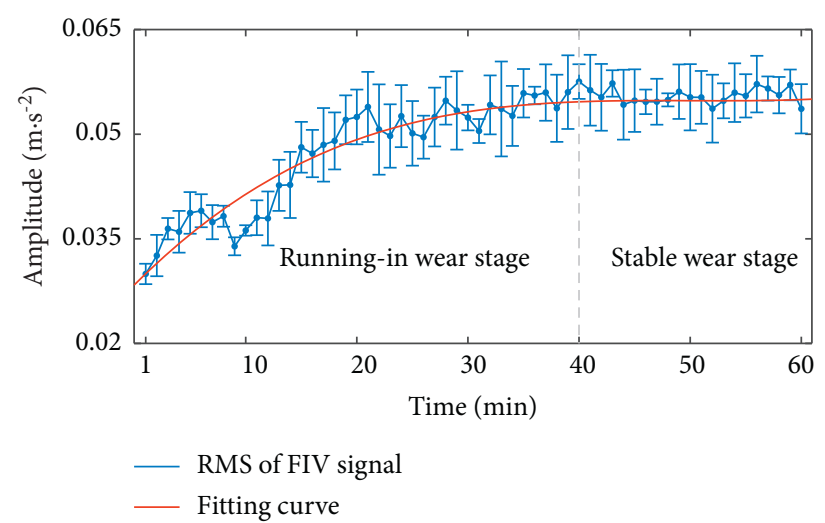

FIgURE 9: RMS value variation of the extracted periodic FIV signal in the running-in experiment.

(2) Stable Wear Stage $(40-60 \mathrm{~min})$. The friction pair entered the stable wear stage from the 40th to 60th minute. In the stable wear stage, the surface roughness of the friction pair remains steady until the end of the experiment. Accordingly, the surface roughness of the ball and disk specimens fluctuated around $0.554 \mu \mathrm{m}$ and $0.279 \mu \mathrm{m}$ separately at the stable wear stage, as depicted in Figure 3. Thus, the composite roughness was stable at around $0.62 \mu \mathrm{m}$ in this stage such that the effective contact area also remained stable. Therefore, the contact between the friction surface was stable. Under a stable contact, the hammering action of the asperities is also stable. Correspondingly, the RMS value of the extracted periodic FIV signals displays a stable trend, as shown in Figure 9.

\section{Conclusion}

In the present work, a running-in experiment of ball-disk friction pair was conducted under lubrication. The HWPT method is used to extract the periodic FIV effectively from the measured vibration signal. The evolution process of the periodic FIV was investigated by the RMS value in the running-in and stable wear stages. Furthermore, the evolution mechanism was discussed with the help of the composite surface roughness. The following conclusions are drawn:

(1) The periodic FIV can be generated under lubrication, whose frequency of the periodic FIV is nearly stable. Moreover, the periodic FIV is weak with low amplitude and often submerged in the background noise. The HWPT is an effective method to extract the periodic FIV in a running-in process.

(2) The RMS increases progressively in the running-in stage and then remains stable in the stable wear stage, which follows the same variation trend as the composite surface roughness of the friction pair. Therefore, the RMS of the periodic FIV signal can be applied to identify the wear stage of a friction pair in practice.

In this research, a severe wear stage is not included. In the future, we will conduct further study on the periodic FIV in a whole wear process under oil lubrication.

\section{Data Availability}

Some or all data including the friction coefficient data and original vibration data, models, and codes that support the findings of this study are available from the corresponding author upon reasonable request.

\section{Conflicts of Interest}

The authors declare that they have no conflicts of interest.

\section{Acknowledgments}

This study was supported by the National Natural Science Foundation of China (grant nos. 51879020 and 51679022), the "Double First-Class" Construction Project (Innovative Project) of Dalian Maritime University (grant no. BSCXXM006), and the Natural Science Foundation of Fujian Province, China (grant no. 2018J01498).

\section{References}

[1] T. Mang, "Run-in," in Encyclopedia of Lubricants and Lubricationp. 1681, Springer Berlin Heidelberg, Berlin, Germany, 2014.

[2] K. Vassiliou, A. P. D Elfick, S. C. Scholes, and A. Unsworth, "The effect of 'running-in'on the tribology and surface morphology of metal-on-metal Birmingham hip resurfacing device in simulator studies," Proceedings of the Institution of Mechanical Engineers, Part H: Journal of Engineering in Medicine, vol. 220, no. 2, pp. 269-277, 2006.

[3] H. Zhu, S. Ge, X. Cao, and W. Tang, "The changes of fractal dimensions of frictional signals in the running-in wear process," Wear, vol. 263, no. 7-12, pp. 1502-1507, 2007.

[4] A. Clarke, I. J. J. Weeks, R. W. Snidle, and H. P. Evans, "Running-in and micropitting behaviour of steel surfaces under mixed lubrication conditions," Tribology International, vol. 101, pp. 59-68, 2016.

[5] Q. Hao, D. Bianchi, M. Kaestner, and E. Reithmeier, "Feature based characterization of worn surfaces for a sliding test," Tribology International, vol. 43, no. 5-6, pp. 1186-1192, 2010.

[6] S. Ray and S. K. R. Chowdhury, "Prediction of contact temperature rise between rough sliding bodies: an artificial neural network approach," Wear, vol. 266, no. 9-10, pp. 1029-1038, 2009. 
[7] H. Y. Li, L. Y. Wang, B. Ma, C. S. Zheng, and M. Chen, "Study on no-load running-in wear of power-shift steering transmission based on oil spectrum analysis," Spectroscopy and Spectral Analysis, vol. 29, no. 4, pp. 1013-1017, 2009.

[8] G. D. Sun and H. Zhu, "Characteristic parameter extraction of running-in attractors based on phase trajectory and grey relation analysis," Nonlinear Dynamics, vol. 95, no. 4, pp. 3115-3126, 2019.

[9] A. Akay, O. Giannini, F. Massi, and A. Sestieri, "Disc brake squeal characterization through simplified test rigs," $\mathrm{Me}$ chanical Systems and Signal Processing, vol. 23, no. 8, pp. 2590-2607, 2009.

[10] R. V. Sorokatyi and A. V. Dykha, "Analysis of processes of tribodamages under the conditions of high-speed friction," Journal of Friction and Wear, vol. 36, no. 5, pp. 422-428, 2015.

[11] C. J. Tu, Z. H. Chen, and J. T. Xia, “Thermal wear and electrical sliding wear behaviors of the polyimide modified polymermatrix pantograph contact strip," Tribology International, vol. 42, no. 6, pp. 995-1003, 2009.

[12] A. Kovalchenko, O. Ajayi, A. Erdemir, G. Fenske, and I. Etsion, "The effect of laser surface texturing on transitions in lubrication regimes during unidirectional sliding contact," Tribology International, vol. 38, no. 3, pp. 219-225, 2005.

[13] A. Akay, "Acoustics of friction," The Journal of the Acoustical Society of America, vol. 111, no. 4, pp. 1525-1548, 2002.

[14] G. Lacerra, M. Di Bartolomeo, S. Milana, L. Baillet, E. Chatelet, and F. Massi, "Validation of a new frictional law for simulating friction-induced vibrations of rough surfaces," Tribology International, vol. 121, pp. 468-480, 2018.

[15] O. Giannini and F. Massi, "An experimental study on the brake squeal noise," in Proceedings of the International Conference on Noise and Vibration Engineering-ISMA, Leuven, Belgium, September 2004.

[16] H. B. Abdelounis, A. Le Bot, J. Perret-Liaudet, and H. Zahouani, "An experimental study on roughness noise of dry rough flat surfaces," Wear, vol. 268, no. 1-2, pp. 335-345, 2010.

[17] C. Ding, H. Zhu, G. D. Sun, Y. K. Zhou, and X. Zuo, "Chaotic characteristics and attractor evolution of friction noise during friction process," Friction, vol. 6, no. 1, pp. 47-61, 2018.

[18] Y. K. Zhou, M. L. Peng, X. Zuo, and J. Xu, "Correlation between friction coefficient and friction vibration in runningin process based on cross recurrence plots," Journal of Tribology, vol. 144, no. 1, Article ID 011703, 2021.

[19] C. Xu, B. Li, and T. H. Wu, "Wear characterization under sliding-rolling contact using friction-induced vibration features," Proceedings of the Institution of Mechanical Engineers, Part J: Journal of Engineering Tribology, 2021.

[20] H. J. Yu, H. J. Wei, J. M. Li, D. P. Zhou, L. D. Wei, and H. Liu, "Lubrication state recognition based on energy characteristics of friction vibration with EEMD and SVM," Shock and Vibration, vol. 2021, Article ID 9972119, 7 pages, 2021.

[21] J. J. Wang and G. X. Chen, "Experimental study on the relation between the contact resonance frequency and frictioninduced noise frequency," Tribology, vol. 34, no. 3, pp. 278284, 2014.

[22] N. P. Hoffmann and L. Gaul, Friction Induced Vibrations of Brakes: Research fields and Activities, SAE International, Warrendale, PA, USA, 2008.
[23] F. Massi, Y. Berthier, and L. Baillet, "Contact surface topography and system dynamics of brake squeal," Wear, vol. 265, no. 11-12, pp. 1784-1792, 2008.

[24] J. L. Mo, Z. G. Wang, G. X. Chen, T. M. Shao, M. H. Zhu, and Z. R. Zhou, "The effect of groove-textured surface on friction and wear and friction-induced vibration and noise," Wear, vol. 301, no. 1-2, pp. 671-681, 2013.

[25] A. Y. Wang, J. L. Mo, X. C. Wang, M. H. Zhu, and Z. R. Zhou, "Effect of surface roughness on friction-induced noise: exploring the generation of squeal at sliding friction interface," Wear, vol. 402, pp. 80-90, 2018.

[26] A. Papangelo, C. Putignano, and N. Hoffmann, "Self-excited vibrations due to viscoelastic interactions," Mechanical Systems and Signal Processing, vol. 144, Article ID 106894, 2020.

[27] J. J. Sinou, J. Cayer-Barrioz, and H. Berro, "Friction-induced vibration of a lubricated mechanical system," Tribology International, vol. 61, pp. 156-168, 2013.

[28] T. Liu, G. B. Li, H. J. Wei, and P. F. Xing, "Stability analysis of tribosystem based on the energy feature of friction vibration," Journal of Tribology, vol. 139, no. 5, 2017.

[29] L. I. Farfan-Cabrera, E. A. Gallardo-Hernández, J. PérezGonzález, B. M. Marín-Santibáñez, and R. Lewise, "Effects of Jatropha lubricant thermo-oxidation on the tribological behaviour of engine cylinder liners as measured by a reciprocating friction test," Wear, vol. 426, pp. 910-918, 2019.

[30] B. J. Hamrock and D. Dowson, "Elastohydrodynamic lubrication of elliptical contacts for materials of low elastic modulus. II-starved conjunction," Journal of Tribology, vol. 101, no. 1, pp. 92-98, 1979.

[31] P. D. Srivyas and M. S. Charoo, "Friction and wear characterization of spark plasma sintered hybrid aluminum composite under different sliding conditions," Journal of Tribology, vol. 142, no. 12, Article ID 121701, 2020.

[32] A. Raina and A. Anand, "Tribological investigation of diamond nanoparticles for steel/steel contacts in boundary lubrication regime," Applied Nanoscience, vol. 7, no. 7, pp. 371-388, 2017.

[33] R. Yan and R. X. Gao, "An efficient approach to machine health diagnosis based on harmonic wavelet packet transform," Robotics and Computer-Integrated Manufacturing, vol. 21, no. 4-5, pp. 291-301, 2005.

[34] S. K. Rhee, P. H. S. Tsang, and Y. S. Wang, "Friction-induced noise and vibration of disc brakes," Wear, vol. 133, no. 1, pp. 39-45, 1989.

[35] Y. F. Mai, Z. L. Liu, S. W. Wang, and B. Y. Dong, "Experimental investigation into friction-induced squeal of rotatingsliding friction," China Mechanical Engineering, vol. 28, no. 18, p. 2198, 2017.

[36] M. Di Bartolomeo, G. Lacerra, L. Baillet, E. Chatelet, and F. Massi, "Parametrical experimental and numerical analysis on friction-induced vibrations by a simple frictional system," Tribology International, vol. 112, pp. 47-57, 2017.

[37] M. K. A. Ali, H. Xianjun, A. Elagouz, F. A. Essa, and M. A. A. Abdelkareem, "Minimizing of the boundary friction coefficient in automotive engines using $\mathrm{Al}_{2} \mathrm{O}_{3}$ and $\mathrm{TiO}_{2}$ nanoparticles," Journal of Nanoparticle Research, vol. 18, no. 12, pp. 1-16, 2016.

[38] M. K. A. Ali, H. Xianjun, L. Mai, C. Qingping, R. F. Turkson, and C. Bicheng, "Improving the tribological characteristics of piston ring assembly in automotive engines using $\mathrm{Al}_{2} \mathrm{O}_{3}$ and 
$\mathrm{TiO}_{2}$ nanomaterials as nano-lubricant additives," Tribology International, vol. 103, pp. 540-554, 2016.

[39] M. P. Rapetto, A. Almqvist, R. Larsson, and P. M. Lugt, "On the influence of surface roughness on real area of contact in normal, dry, friction free, rough contact by using a neural network," Wear, vol. 266, no. 5-6, pp. 592-595, 2009.

[40] Q. Chen, S. W. Huang, Z. Zhang, and M. M. Qiu, "Research on fractal contact model for contact carrying capacity of two cylinders' surfaces considering friction factors," Journal of Mechanical Engineering, vol. 52, no. 7, pp. 114-121, 2016. 